\title{
Spatio-Temporal Geomorphic Landscape Dynamics and Possible Geological Hazards in Ghana
}

\author{
Ezekiel Addison Otoo ${ }^{1 *}$, Yaw Asamoah $(\mathrm{PhD})^{1}$, George Boateng ${ }^{2} \&$ Ishmael Yaw Dadson $(\mathrm{PhD})^{1}$ \\ ${ }^{I}$ Department of Geography Education, University of Education, Winneba, Ghana \\ ${ }^{2}$ Berekum College of Education, Berekum - Ghana \\ *Correspondence
}

\begin{abstract}
The recent deteriorating nature of the Mile 11 hills has made the area a potential geo-hazard zone given the extent of human activities and the level of excavations on-going. The study sought to investigate the extent of landscape change and possible geological hazards between 1986 and 2016. It adopted the exploratory sequential design and the mixed research methodology. The study used spatial cartographic tools (GIS and Remote Sensing) to examine the extent of landscape change as well as interviewed 32 participants (residents and experts) for the qualitative analysis through the purposive sampling method. The results confirmed the landscape was undergoing both degradation and depositional geomorphic changes. About $56.11 \%$ of the landscape underwent degradation while $43.89 \%$ underwent deposition. Geomorphic change in the municipality was largely due to anthropogenic change rather than geological changes which were evidence by the activities of urbanisation, sand winning and quarrying on-going in the area, posing potential geo-hazard risk to residents in the area. The major factors found to be responsible for landscape change included geological, meteorological, and anthropogenic factors. Possible geological hazards envisaged included earth quake, landscape influenced flooding and mudflow. It was recommended that hazard prone areas should also be zoned and residents relocated to prevent future fatalities. Proper coordination was also recommended between traditional land owners, EPA, GGSA and GSMA to enhance proper planning in the municipality.
\end{abstract}

Keywords: Spatio-temporal, Geomorphic landscape, geological hazards, GIS, Remote sensing.

\section{INTRODUCTION}

$\mathrm{L}$ andscape structure and composition develops continuously in space and time. These developments are attributable to the complex interaction between the natural environment and human activities, resulting in the change of the stability of individual elements in the landscape system and the spatial structure of the landscape (Xiao et al., 1990).

Landscape dynamics also called landscape change, is the process of landscape evolution, tracing the relationship between humankind and the natural environment. It is related to land use land cover (LULC) change (Potter \& Lobley, 1996), which views landscapes as a holistic entities which reflects physical and cultural influence (Antrop, 1998). Antrop (2005) defends that landscape could be understood as the way and aim in which human societies use the land resource, creating patterns that can alter the natural processes and modify the natural evolution of the landscape. Landscape dynamics fundamentally focus on the relationship between humans and their interaction in space. Their interaction should focus on the healthy and harmonious balance between humans and the environment.

Recent trends of spatial re-organization coupled with the economic, climatic and environmental crisis have been altering the face of the land worldwide. Landscapes around the world, old or new, prominent or mundane, are increasingly under threat of being irreparably lost. They affirmed that, the Mediterranean landscape was modified by men for centuries which resulted in a more homogeneous habitats, specific habitats and species extinction. (Van der Sluis et al., 2012)

In Africa, Hurni and Wiesman, (2010) noted that Ethiopia is experiencing a drastic landscape change where more than $90 \%$ of its highlands which were once forested; currently have a forest cover of less than $4 \%$. Ghana, like most Africa countries is undergoing a rapidly increasing landscape change which poses threat to its sustainability (Antwi et al., 2014). In the last four decades, the capital city of Ghana, Accra, has seen a large amount of landscape changes, as a result of lack of proper planning. This has led to intricate serious problems such as soil erosion, deforestation and flooding (Yeboah et al., 2017).

The Mile 11 catchment in recent times has become a potential geo-hazard zone given the extent of human activities on the hills and the level of excavations. The influx of people into the Mile 11 catchment have resulted in various human activities including settlement, stone quarrying and sand mining. This has resulted in terracing of the slope which increases the steepness of the slope and the possibility of geohazard in the area (EPA, 2018).

Several warnings from experts in geological observation and management authority seem to have fallen on death ears. The Ghana Geological Survey Authority warned that a major catastrophe awaits the area if the massive development going on in the settlement is not controlled. It was also emphasised that all the debris by the roadside was coming from the surface of the mountain and if it rains continuously and the mountain gets soaked so much, we could have a major mudflow coming down and all those buildings quite close to the mountain will end up in a disaster" (Daily Graphic, 2015).

The Ghana Institution of Engineers (GhIE) also warned that a similar underlying geological factors in Sierra Leone, Free Town caused the death of more than one thousand residents 
on November $18^{\text {th }}, 2017$ following a three days of continues rainfall. The problem lies in the facts that despite the numerous cautions issues by geological experts and the fact that the process of diastrophism is continuously multiplying in the area, which could trigger likely early geological hazard at any given time, the area still remains a preferred location for residential dwelling. Understanding the spatiotemporal landscape status of an area is an important step to implementing future conservation measures (Suleiman et al., 2014).

It is against this background that the study sought to investigate the evolution of landscape and estimate possible geomorphic hazards in the study area within a speculated period from 1986 to 2016.

\section{METHODOLOGY}

The study was confined within the Ga South municipality in the Greater Accra Region of Ghana. In terms of absolute location, the Ga South municipal area lies within latitude $5^{\circ} 48$ North, $5^{\circ} 29$ North, longitude $0^{\circ} 8$ West and $0^{\circ} 30$ West. The area is underlined by shallow rocky soil with extensive steep slopes which is composed of basic gneiss inselbergs, which forms part of the Accraian, Togo and Dahomeyan formation (Amponsah, 2004). The area has a projected population of 521,162 by the end of 2020 , with a growth rate of $3.1 \%$ and a population density of 1524 persons per kilometre square (GSS, 2013). The study utilized an exploratory-sequential case study design relying on both qualitative (Geographic Information Science and Remote Sensing) and quantitative techniques (the interviews and case histories). The quantitative data projected the nature of the landscape for the next ten years (2026). The study targeted residents who were more than eighteen (18) years of age and had lived in the community for at least 10 years. The target included traditional authorities as well as officials from the Environmental Protection Agency (EPA), the Ga South Municipal Assembly (GSMA), Ghana Meteorological Agency and the Ghana Geological Survey Authority (GGSA). Thirtytwo (32) respondents were sampled and interviewed using the purposive sampling. Twenty-four (24) residents who fell within the selection criteria were selected for a focused group discussion while the expert based purposive sampling technique was used to select eight (8) experts. The study adapted spatiotemporal techniques with cartographic analysis at different spatial time scales. Digital data set of elevation (through a $10 \mathrm{~m}$ Digital Elevation Model [DEM]) for the years 1986 and 2016. The qualitative data was analysed using thematic analysis to identify and draw patterns within data. The quantitative data was analysed using spatial analysis tools including ArcGIS 10.5, ERDAS IMAGINE 2013, and Google Earth Pro. Statistical diagrams such as bar graphs, pie chart, histogram etc. and Cartographic images, maps and pictures were used to present and analyse the data.

\section{RESULTS AND DISCUSSION}

Dynamics of landscape change from 1986 to 2016
The change in elevation realised from statistically information gathered in the municipality proves that the municipality's landscape is undergoing a rapid geomorphic change which includes both degradation (denudation) and aggradation (deposition).

Data evidence from statistically classified elevations shows that 23.1 hectares of land were below sea level that is 0 feet in the year 1986. This figure decreased to 21.6 hectares in 2016, which implies that 1.5 hectares of land has further undergone denudation to fall below sea level. In 1986, 14141.4 hectares of land had an elevation between 0-100 feet but decreased by 27 hectares leaving 14114.4 hectares of land between 0-100 feet. Elevation between 100-200 feet also witnessed a decrease of 13.3 hectares between 1986 and 2016 from 10503.8 hectares to 10490.5 hectares. By 2016, elevations between 200- 300 feet had increased tremendously by 63 hectares leaving the current size at 5835.1 hectares compared to its size of 5772.1 hectares in 1986. The year 2016 saw an increase in elevations between 300-400 feet from 2667.8 hectares in 1986 to 2669.8 hectares in 2016, indicating an increase of 1.9 hectares of land. Elevations between 400-500 feet had decreased by 3.0 hectares by 2016 leaving the current size at 989.8 hectares from the initial 992.8 hectares in 1986. By 2016, there had been a drastic decrease of 20.4 hectares between elevations classified 500-600 feet leaving it current size at 236.2 hectares from its initial size of 256.6 hectares in 1986. The year 1986 had 64.5 hectares of land above 600 feet, this increase to 64.9 in 2016 implying an aggradation of 0.4 hectares.

\section{Geomorphic Change Analysis between 1986 and 2016}

Using the specified classification scheme below the study sought to discover areas of denudation (degradation) and areas of aggradation (deposition). Evidence from (Table 1) revealed that no spot of the municipality remained unchanged in terms of elevation between 1986 and 2016 per the classification scheme used. Between the 30 years period, 251 hectares of land in the municipality experienced very high degradation. This implies that 251 hectares of land had an elevation decrease below -45 feet indicating very high degradation. Places of high degradation (-45 to -30.01 feet) represented 336.3 hectares of land, while places of medium high degradation (-30 to -15.01 feet) made up 1727.3 hectares of land. 16968.7 hectares of land was discovered to be of low degradation (-15 to 0.01 feet), which is the largest degradation class witnessed in the municipality within the study periods. In all about 19313.3 hectares of land underwent denudation which represents $56.11 \%$ of the total land area in the municipality.

Places which saw an increase in their elevations between 0.01 and 15 feet (low deposition) was 12804.8 hectares (which was the largest deposition class) whiles those with medium high deposition (15.01 to 30 feet) represented 1588.5 hectares of land. High deposition areas (30 to 45 feet) covered 413.1 hectares of land whiles those with very high deposition (45 feet and above) represented 302.4 hectares. In total, 15108.9 
hectares of land which represented $43.89 \%$ underwent some form of deposition between the study periods. It was discovered per the statistical data gathered that $86.05 \%$ of the total change in elevation was between low degradation ( -15 to -0.01 feet) and low deposition ( 0.01 to 15 feet), while only $6.8 \%$ underwent degradation above 15 feet and $6.7 \%$ underwent deposition above 15 feet. This dynamics or changes in elevation could be attributed to the expanding activities of sand mining and quarrying as well as the rapid urban expansion in the municipality (which is proven from residential and expert interactions as well as observations carried out in some part of the municipality). Those activities in one way or the other causes either denudation or aggradation in the municipality.

\section{Elevation change projection for 2026}

Projections were made for elevation in the next ten years using the current changing trend of elevation between 1986 and 2016. According to the projected results (evidence in Figure 1) about 21.1 hectares of land will fall below sea level by the year 2026. The projection shows that 14105.5 hectares will be between 0 to 100 feet, 10486 hectares between 101 to 200 feet, 5856.1 hectares between 201 to 300 feet, 2670.3 hectares between 301 to 400 feet, 988.8 hectares between 401 to 500 feet, 229.4 hectares between 501-600 feet and 65 hectares above 600 feet. Analysis from the record shows that about $71.4 \%$ of the total land size will be between 0 to 200 feet above sea level.

\section{Implication of elevation change and projection on geo-} hazards

Evidence from Table 1 brings to discovery that as the rate of degradation increases (from low degradation through to very high degradation) the size of land affected decreases. In that same manner as the rate of deposition increases from low deposition to very high deposition the size of land affected decreases. This could contribute to the reasons why some residents do not see the intensity of the problem of elevation dynamics in the area. This is because majority of the areas which is being degraded are within low degradation hence residents see them as insignificant.

The decreasing elevation in major portions of the municipality is an evidence of the activities of sand winning and quarrying in the municipality. Slope undercutting from quarries, mines, road construction etc. depletes the area of vegetation which can weakens the geological stability of the area. Slope undercutting also increases the convexity and gradient of the slope rendering it susceptible to slope failure (UNESCO, UNEP, 1988). This is also confirmed by EPA in their assertion that the increase in the steepness of slopes can trigger the possibility of geo-hazard in an area (EPA, 2018).

Quarrying activities causing vibrations in the slope further weakening particle bonding, create and could expand fault lines or lines of weakness within the earth crust which could facilitate likely earth tremors and other geo-hazards such as rock fall, mudflow etc.
Above $72 \%$ of the total land area being below 200 feet by 2026 implies the high proneness of the municipality to flood. The few surrounding higher lands will direct heavy rain water runoff which is not able to infiltrate into the ground to low lying areas and cause the low lying areas to flood during heavy down pour.

The adoption of the terracing system in some high raising areas in the municipality could contribute to the reshaping of the local territorial landscape. Unplanned terraced lands can make some low lying area more susceptible to the effect of mass wasting. When terrace is unmaintained and it is over saturated, it could decrease the water holding capacity of the land hence making the area more liable to mud flow in the cause of heavy rainfall. This is in line with Sidle, Pearce, and O'Loughlin (1985) claim that soil stability are influenced the rate of water movement in soil and the capacity of the soil to hold water, hence its failure to hold extra water can lead to mud flow.

\section{Possible geological hazards triggered by landscape change}

Some of the possible geological hazard stated by the participants to be likely to hit the area included mud flow, massive erosion, flooding, earth quake, landslide, rock fall among others.

This objective was achieve through rigorous focus group discussion (FGD) with residents and traditional Authorities in the area, as well as environmental and geological experts including officials from the Environmental Protection Agency, the Ga South Municipal Assembly, Ghana Meteorological Agency and the Ghana Geological Survey Authority. Some of the possible geological hazard stated by the respondents to be likely to occur in the area included mud flow, massive erosion, flooding, and earthquake, among others. These views are captured in the expressions shared by some respondents as follows;

\section{Earth Tremor and Earth Quake}

Earth tremor seemed not new to most residents in the area. Vibrations within the earth crust was confirmed to be occurring quiet frequent in recent times. Testimonies from residents and experts revealed the fact that the area was not far from a possible earth quake in the coming days. In an interaction with an official from the EPA it was revealed that the area had experience several earth tremors between December, 2018 and March, 2019.

It was also found from the study that the frequent quarrying and sand mining coupled with the massive development in the area has caused disequilibrium in the geological structure of the rocks in the area. This claims has widened the fault line in the area and could contribute to the recent frequent earth tremors being experienced in the area. In the view of an expert official, if this continues an earthquake should be expected in no time. 


\section{Flooding and Erosion}

Some residents shared their experience on flooding and soil erosion they have witnessed in the past and discussed what they could expect in the future. Seasonal flooding and massive erosion in the area was not new to most respondents. They claim the seasonal spillage of the Weija dam coupled with excessive rainfall erodes the soil and causes flood during the rainy season.

A-Nature of road during the dry season

B-Nature of road during the rainy season

C-Loads of sand from the top of the hill blocking the main Kasoa-Accra road

D-Poor nature of roads in the community as a result of erosion

Plate 1: Effects of changing landscape in the study area

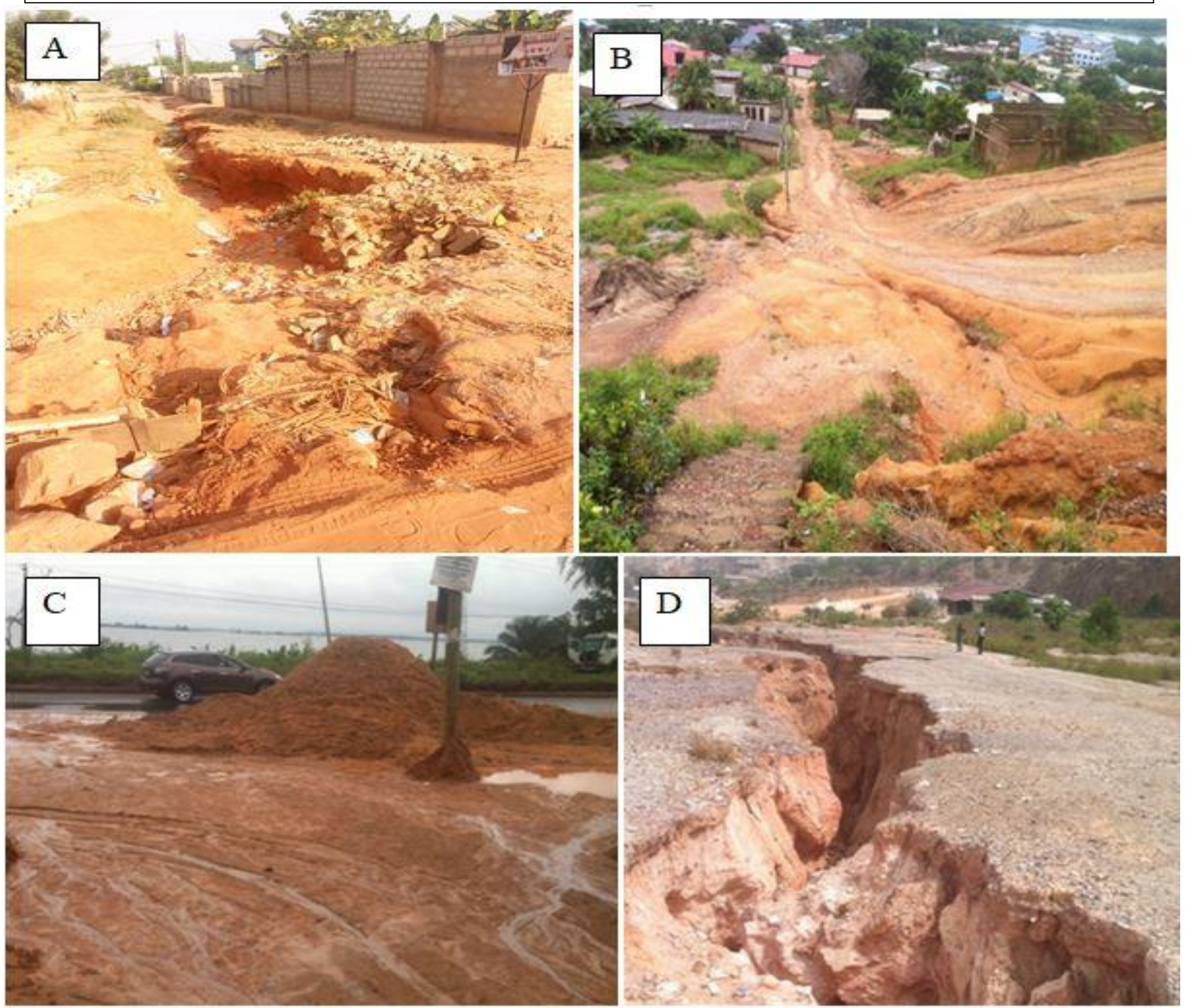

\section{Mud flow or Soil flow}

Respondents also expressed their experience on rampant mudflow in the area especially during the rainy seasons. Residents and expert discussion revealed that mudflow was one of the most common geological hazard witnessed in the area. Residents expression and gestured showed emphasised that they were very worried about the rampant nature of mudflow in the area and some feared its consequence in the future. Some residents blamed the massive depletion of vegetation in the area as the cause of the persisting problem of frequent mudflow.

\section{CONCLUSION}

Landscape change is undoubtedly linked with anthropogenic activities. Due to readily available land in some mountain areas residents use it intensively without the thought of 
sustainability and hazard risk. The current landscape in the Ga South Municipality is undoubtedly not sustainable and could cause further hazards in future. The rate at which the landscape is adversely changing is not compatible with sustainable landscaping. Radical steps should be taken by the national government and municipal assembly to evacuate and relocate residents in the area in order to prevent any possible future effect of geological hazard to hit the area.

It was recommended that further investigations should be done to evaluate the impacts of landscape dynamic on residents in the municipality. Livelihood strategies should be diversified to incorporate other pay sources outside sand winning and quarrying that can give more incentive than geologic depletion based occupations. There should be a proper coordination between traditional land owners, EPA, GGSA and the GSMA towards the acquisition and sales of land to enhance proper planning in the municipality. Finally, it is prescribed that Ghana builds up an urban development policy. The focal point of such strategy ought to be the maintenance a reasonable balance between urban infrastructure development, ecological sustainability, and geological sustainability.
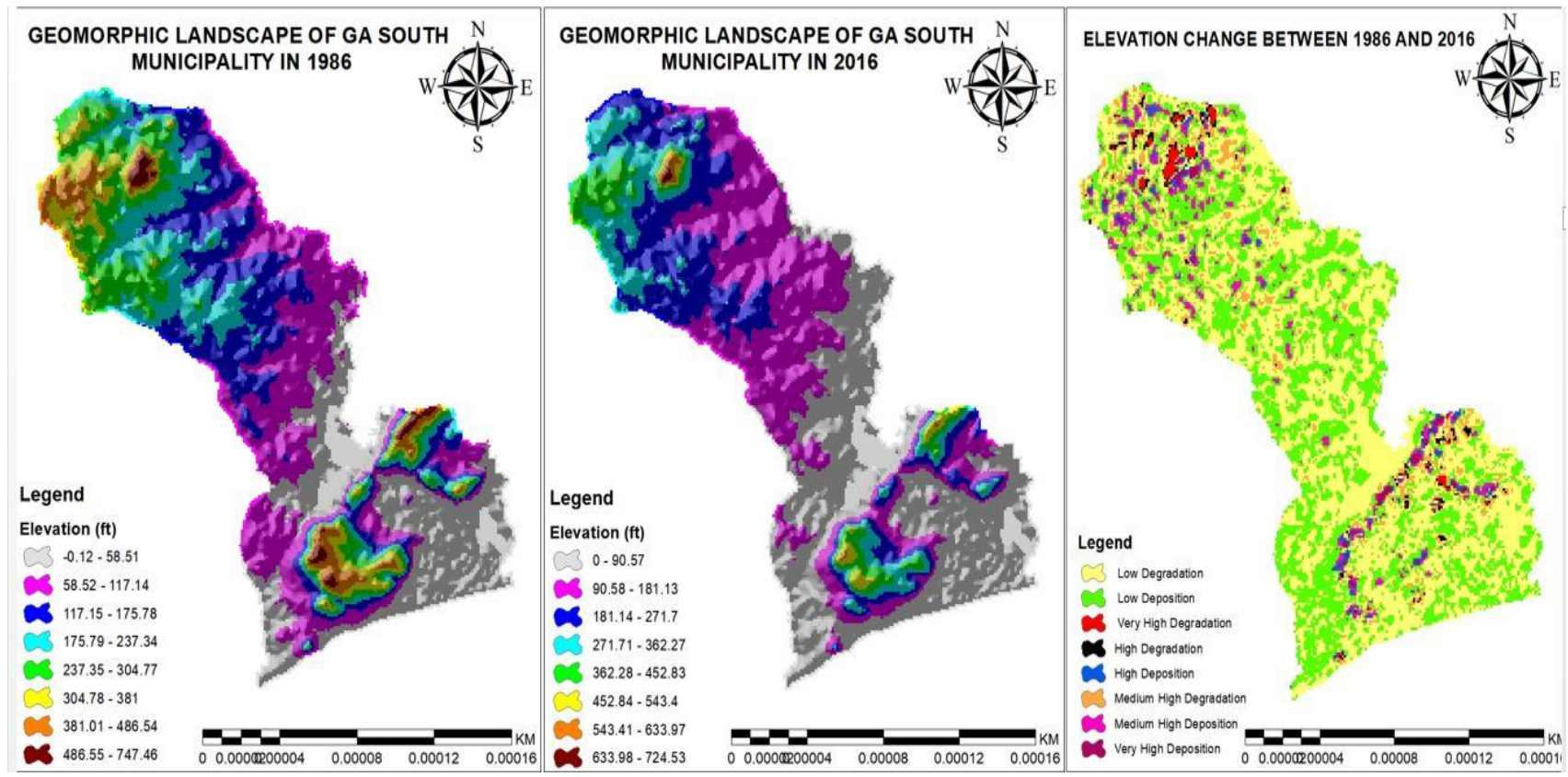

Figure 1: Elevation change maps

Table 1: Elevation Change Classification and Size

\begin{tabular}{|c|c|c|}
\hline \multicolumn{3}{|c|}{ Elevation Change Classification and Size } \\
\hline Elevation Classification (feet) & Change (hectares) & Total Degradation/Deposition \\
\hline Very High Degradation ( Below -45.01) & 251.0 & \multirow{4}{*}{ 19313.3 hectares $(56.11 \%)$} \\
\hline High Degradation (-45 to -30.01$)$ & 366.3 & \\
\hline Medium High Degradation (-30 to -15.01$)$ & 1727.3 & \\
\hline Low Degradation $(-15-0.01)$ & 16968.7 & \\
\hline Low Deposition $(0.01-15)$ & 12804.8 & \multirow{4}{*}{ 15108.9 hectares $(43.89 \%)$} \\
\hline Medium High Deposition (15.01 - 30) & 1588.5 & \\
\hline High Deposition (30.01 - 45) & 413.1 & \\
\hline Very High Deposition (45.01 and Above) & 302.4 & \\
\hline No Change (0) & 0 & \\
\hline Total & 34422.2 & 34422.2 \\
\hline
\end{tabular}




\section{REFERENCES}

[1] Abbott, P. L. (2002); Natural Disasters. Boston; McGraw-Hill.

[2] Acosta T. V, Schildgen T. F, Clarke B. A, Scherler D, Bookhagen B, Wittmann H, Blanckenburg F, and Strecker M. R(2015), Effect of vegetation cover on millennial-scale landscape denudation rates in East Africa, ResearchGate,

[3] Alexander, D. (1993). Natural Disaster, London, University College Library Press.

[4] Amponsah, P. E (2004) Seismic activities in Ghana: past, present and future, Annals of Geophysics, Vol. 47 No 2/3 pp. 539-43.

[5] Antrop M (2005). Why landscapes of the past are important for the future? Landscape Urban Planning 70:21-34

[6] Antrop M. (1998). Landscape change: plan or chaos, Landscape and Urban Planning, 41, pp.

[7] Bassett, T. J., 2001: The Peasant Cotton Revolution in West Africa: Co`te d'Ivoire 1880-1995. Cambridge University Press, $268 \mathrm{pp}$

[8] Crozier, M. J. (1984) Field Assessment of Slope Instability in D Brunsden and D Prior (eds) Slope Instability, New York, John Wiley and Sons Ltd.

[9] Cruden, D., (1991.) A simple definition of landslide. Bulletin IAEG. 43: 27-29.

[10] Daily Graphic, 19 June, 2015.

[11] Environmental Protection Agency (2018). EPA Year in Review 2017-2018 report

[12] Farina, A. (2006), Principles and methods in landscape ecology, Dordrecht, the Netherlands: Springer.

[13] Finka, M, Kozová, M. \& D. Petríková (2009). Transforming landscape interactive processes between landscape and society in central Europe, In: J. Breuste, M. Kozov \& M. Finka (eds.): European Landscapes in Transformation: Challenges for Landscape Ecology and Management, European IALE Conference, Salzburg (Austria), Bratislava (Slovakia), 45-48.

[14] Frimpong, A. (2011). Application of Remote Sensing and GIS for Forest Cover Change Detection (A case study of Owabi Catchment in Kumasi, Ghana) M.Phil Thesis, KNUST.

[15] Frimpong, E. (2007) retrieved on 20/08/2018 from http//www.enochdarfahfrimpong.blogapot.com

[16] Ghana Statistical Service (2013), 2010 population and housing census, a summary of special report on urban localities, Accra, Ghana.

[17] Hanson, H., Aarninkhof, S., Capobianco, M., Jiménez, J. A., Larsom, M., Nicholls, R. J., Plant, N. G., Southgate, H. N., Steetzel, H. J., Stive, M. J. F. \& de Vriend, H. J., (2003). Modelling coastal evolution on yearly to decadal time scales. Journal of Coastal Research, 19(4) 790 - 811.

[18] Hurni, H, Wiesman, U. M., (2010). Global Change and Sustainable Development: A Synthesis of Regional Experiences from Research. Bern, Switzerland: Geographica Bernesia; 2010:187-207.

[19] Kitutu, M. G., Muwanga, A. Poesen, J and Deckers J. A, (2009) Influence of soil properties on landslide occurrences in Bududa district, Eastern Uganda, African Journal of Agricultural Research Vol. 4 (7), pp.611-620, Available online at http://www.academicjournals.org/AJAR ISSN 1991-637x.

[20] Msilimba, G. G., and Holmes, P. J.,(2005). A Landslide Hazard Assessment and Vulnerability Appraisal Procedure; Vunguvungu/Banga Catchment, Northern Malawi. Natural Hazards 34, 199-216.

[21] Otoo, E. A. (2017), Residents' perception of granite outcrops in parts of Winneba Township. Department of Geography Education, University of Education, Winneba, Ghana. (Unpublished research work)

[22] Suleiman, Y.M., Saidu, S., Abdulrazaq, S.A., Hassan, A.B., Abubakar, A.N. (2014). The dynamics of landuse land cover change: using geospatial techniques to promote sustainable urban development in Ilorin Metropolis, Nigeria. AREES. 2014;1:8-15.

[23] Van der Sluis, T., Kristensen, S.B.P., Frederiksen, P., Cosor, G., Vădineanu, A., Pavlis, E., Terkenli, T.S., Gaube, V., Vesterager, J.P., (2012). Landscape change processes in case study areas (WP2), VOLANTE Project reports. Deliverable no: 2.3 .
http://volanteproject.eu/images/stories/DELIVERABLES/VOLAN TE_D2.3_Landscape_change_processes_in_case_study_areas.pdf. ALTERRA, Wageningen, p. 87

[24] Wiens, J.A. 2005: Toward a unified landscape ecology: Issues and perspectives in landscape ecology. Cambridge University Press, Cambridge: $365-373$.

[25] Xiao, D., Zhao, Y., Sun, Z., Zhang, H., (1990). Study on the variation of landscape pattern in the west suburbs of Shenyang. Chinese Journal of Applied Ecology, 1: 75-84 (in Chinese).

[26] Yeboah F., Awotwi A., Forkuo E.K., \& Kumi M., (2017). Assessing the land use and land cover changes due to urban growth in Accra, Ghana. Journal of Basic and Applied Research International 22(2): 43-50 